\title{
A Facile Method to Prepare Silver Nanoparticles and its Application on
}

\section{Cotton Fabrics}

\author{
Yan Liu ${ }^{1,2, a}$, Xiao-Liang Gao ${ }^{1,2, b}$, Shu-Dong Wang ${ }^{1,2, c}$
}

1. College of Textile and Clothing, Yancheng vocational Institute of Industry Technology, Yancheng, Jiangsu 224005, China; 'Jiangsu R\&D Center of the Ecological Textile Engineering \&Technology, Yancheng vocational Institute of Industry Technology, Yancheng, Jiangsu China.

aycfyfgxly@126.com, ${ }^{b} x z h g x \mid @ 126 . c o m,{ }^{c}$ sdwang1983@163.com

Key words: multi-amino compound $\left(\mathrm{RSD}-\mathrm{NH}_{2}\right)$, silver nanoparticles(Ag NPs), cotton fabric, antibacterial, treated

Abstract : In order to develop a simple and facile method to fabricate a stable and even silver nanoparticles (Ag NPs) colloid solution, the multi-amino compound ( $\left.\mathrm{RSD}-\mathrm{NH}_{2}\right)$ as a highly effective self-reducing agent was used to reduce silver ions to Ag NPs. The Ag NPs showed a spherical structure with diameter of around $10 \mathrm{~nm}$, and its absorption peak was about 420nm. When the cotton fabrics were treated by the solution, the Ag NPs distributed uniformly on the surface and the treated fabrics had an obvious absorption peak around 420nm and excellent antibacterial rates before and after washings. Even if the concentration of the $\mathrm{AgNO}_{3}$ colloidal solution was lower with $0.017 \mathrm{~g} / \mathrm{l}$, the antimicrobial ability of cotton fabrics still showed an excellent antibacterial property and satisfied whiteness. After washed 20 times, the ratio of antibacterial activities were still more than $98.98 \%$ for S.aureus and $99.02 \%$ for E. coli, the corresponding whiteness increased from 82.17 to 86.56.In addition, the ultraviolet resistance of nano-silver treated cotton fabrics improved, the value of UPF changed from 1.7 to 22.7 .

\section{Introduction}

Nano silver is an important kind of nano metal materials which attracted more attentions for many years due to its excellent properties, such as high antibacterial activity, photoluminescence property and conductive activity. It has been used in various fields such as medicine [1], textile fabrics[2], etc. Owing to its wide applications, different kinds of synthetic methods have been fabricated. One of the most important and wide used methods is the chemical reduction which used a reducing agent to fabricate silver particles on a silver salt solution. UV irradiation or $\gamma$-ray was also utilized as an alternative to reduce the silver ions[3,4]. In these studies, controlling the generation and size of the nano-silver particles were always difficult and steps was complex. Therefore, exploring a simple and facile method to prepare a stable and even nano-silver solution became a hot research topic.

Due to the unique chemical and physical properties, hyperbranched polymers have received much attention over the past few decades. Zhang, et,al. prepared nanoparticles of silver by reduction of silver nitrate solution with amino-terminated hyperbranched polymer, which was synthesized from methyl acrylate and diethylene triamine[5]. In this paper, a multi-amino compound (RSD- $\mathrm{NH}_{2}$ ) with a large number of amino groups and imino groups (Figure 1), was fabricated by methacrylate and polyethylene polyamine with the presence of methanol, which can reduce silver ions to Ag NPs 
[6]. In addition, the $\mathrm{RSD}-\mathrm{NH}_{2}$ acted as a stabilizer by preventing nanoparticles from agglomerating. The formation of silver colloid nanoparticles was characterized by Dynamic light scattering (DLS), Transmission electron microscopy (TEM) and UV/Visible absorption spectrophotometry. The antibacterial property against Escherichia coli (E.coli) and Staphylococcus aureus (S. aureus) and ultraviolet resistance of cotton fabrics were studied.

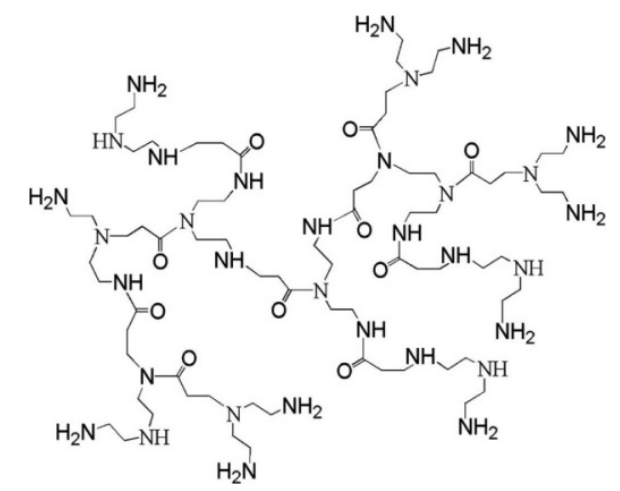

Figure 1. Schematic description of the RSD-NH${ }_{2}$ 's molecule structure

\section{Experiments}

\section{Materials}

The slurry of cotton fabrics and multi-amino compound(RSD- $\mathrm{NH}_{2}$ ) were prepared in laboratory. Methacrylate, polyethylene polyamine, methanol, sodium sulfide $\left(\mathrm{Na}_{2} \mathrm{~S}\right)$, silver nitrate $\left(\mathrm{AgNO}_{3}\right)$, nitric acid $\left(\mathrm{HNO}_{3}\right)$,Nutrient broth and nutrient agar were purchased from Shanghai Chemical Reagent Co, Ltd. S.aureus (ATCC 6538) and E. coli (ATCC 8099) were obtained from of Department of chemical engineering, Yancheng Institute of Industry Technology(China).

\section{Synthesis of the Ag NPs and its finishing method on cotton fabrics}

Silver nitrate $\left(\mathrm{AgNO}_{3}\right)$ and the multi-amino compound $\left(\mathrm{RSD}-\mathrm{NH}_{2}\right)$ were dissolved in deionized water, separately. Then $\mathrm{AgNO}_{3}$ aqueous solution was added into the RSD- $\mathrm{NH}_{2}$ solution under vigorous stirring. The initial concentrations of the reaction components were $0.017,0.085$ and 0.17 $\mathrm{g} / \mathrm{l}$ for $\mathrm{AgNO}_{3}$ and $2 \mathrm{~g} / \mathrm{l}$ for $\mathrm{RSD}-\mathrm{NH}_{2}$. The reacting mixture was kept stirring at room temperature until reduction of $\mathrm{Ag}+$ to $\mathrm{Ag}$ was completed and brown Ag NPs appeared.

The cotton fabrics were immersed into the nanosilver colloid solution (with the bath ratio of 1:50)with constant stirring for $10 \mathrm{~min}$ at room temperature, then washed with tap water several times to remove unfixed materials. The resulting cotton fabrics were air-dried at ambient temperature to produce nano-silver finished cotton fabrics.

\section{Test methods for Ag NPs and its treated cotton fabrics}

Dynamic light scattering(DLS) using a HPPS 5001 grain size analyzer and Transmission electron microscopy (TEM) micrographs were used to characterize the size distribution, dispersity and morphology of the Ag NPs. UV-visible (UV-vis) absorption spectra were recorded using an UV-3010 spectrophotometer to show the absorption spectrum of nano-silver solution. Model JSM scanning electron microscope (SEM) was used to observe the particles size and morphology of Nano silver particles on the surface of cotton fabrics. K/S absorption spectra of treated cotton fabrics were tested under a D65 illuminant at $10^{\circ}$ observer using an Ultrascan XE spectrophotometer. An ultraviolet transmission analyzer (LabspHere UV 2000S, USA) was used to test the fabric's ultraviolet protection factor (UPF) and transmittance of UV radiation according to GB/T 18830-2009. The antibacterial activity and the durability of the nano-silver treated cotton fabrics were tested against E. coli and S. aureus by using a shaking flask method according to FZ/T 
73023-2006 (China). This method is specially designed for specimens treated with the antibacterial agents under dynamic contact conditions. The percentage reduction was determined as follows:

Reduction in cfu $(\%)=\frac{\mathrm{A}-\mathrm{B}}{\mathrm{A}} \times 100$

where, A and B are the bacterial colonies of the original cotton fabrics and Ag NPs treated cotton fabrics, respectively.

\section{Results and discussion}

\section{Synthesis of the Ag NPs in solution}

Figure 2 showed the TEM images and corresponding histograms of silver colloid nanoparticles with three different initial $\mathrm{AgNO}_{3}$ concentrations. The shape of $\mathrm{Ag}$ NPs were spherical, when the concentration of $\mathrm{AgNO}_{3}$ increased from $0.017 \mathrm{~g} / \mathrm{l}$ to $0.17 \mathrm{~g} / \mathrm{l}$, the mean particle sizes of nano-silver particles stayed at about $10 \mathrm{~nm}$, and the amount and the size of silver particles increased a lot. The mean size of Ag NPs tested by TEM images was consistent with the results of DLS.
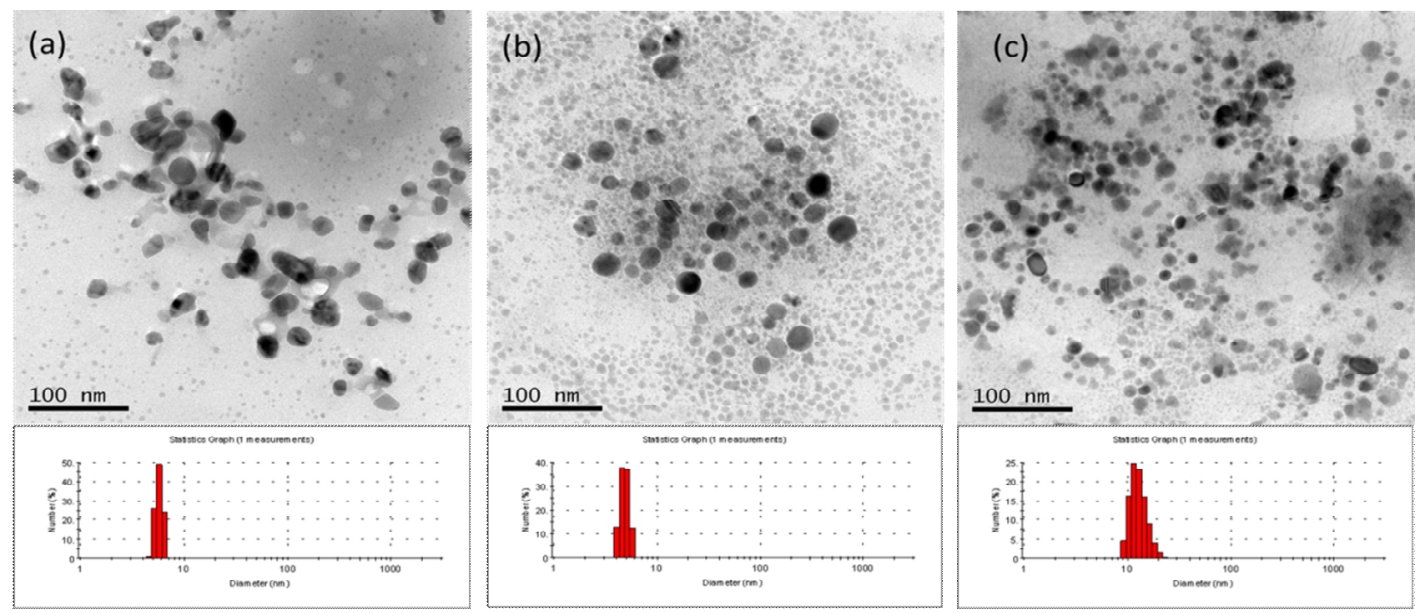

Figure 2. TEM images and corresponding histograms of silver colloid nanoparticles, $\left[\mathrm{AgNO}_{3}\right]=0.017 \mathrm{~g} / \mathrm{l}$ (a), $0.085 \mathrm{~g} / \mathrm{l}(\mathrm{b}), 0.17 \mathrm{~g} / \mathrm{l}(\mathrm{c}),\left[\mathrm{RSD}-\mathrm{NH}_{2}\right]=2 \mathrm{~g} / \mathrm{l}$.

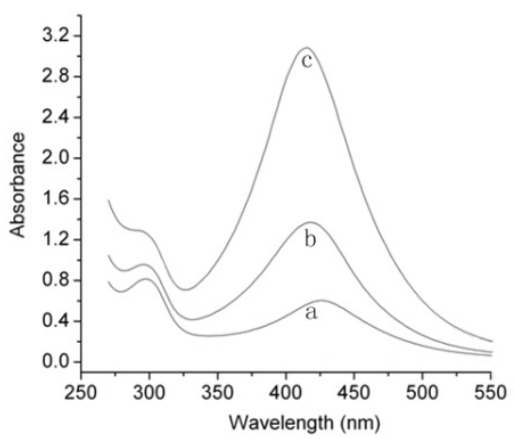

Figure 3. UV-vis spectra of silver colloid nanoparticles, $\left[\mathrm{AgNO}_{3}\right]=0.017 \mathrm{~g} / \mathrm{l}(\mathrm{a}), 0.085 \mathrm{~g} / \mathrm{l}$ (b) , $0.17 \mathrm{~g} / \mathrm{l}$ (c), $\left[\mathrm{RSD}-\mathrm{NH}_{2}\right]=2 \mathrm{~g} / \mathrm{l}$.

Figure 3 showed the UV-vis spectra of $\mathrm{Ag}$ NPs recorded at different $\mathrm{AgNO}_{3}$ concentration. From the spectra, two absorption peaks exist, respectively, at about 290nm and 420nm. The $298 \mathrm{~nm}$ absorption peak observed due to pure RSD-NH${ }_{2}$, while the $420 \mathrm{~nm}$ was the silver nanoparticle's 
absorption peak. As the concentration of $\mathrm{AgNO}_{3}$ increased, the value of absorption peak of $\mathrm{Ag}$ NPs appeared more obviously and its positions shifted, which indicated the growing size and amount of Ag NPs. The information on Figure 2 and Figure 3 indicated that the Ag NPs can be successfully synthesized through the reaction between $\mathrm{AgNO}_{3}$ and $\mathrm{RSD}-\mathrm{NH}_{2}$.

\section{Morphology of the Ag NPs treated Cotton fabrics}

The morphology and size of the silver nanoparticle had a greater influence on the structure and performance of the treated fabrics. Figure 4 showed the SEM images of the cotton fabrics' surface before and after treatment by the Ag NPs. It could be seen from Figure 4(a) that the untreated cotton fiber surface was clean and smooth. However, it became rough and was covered by nano silver colloidal particles in Figure 4(b). The particles distributed uniformly on surface of the treated cotton fibers, which may cause the fiber with the possibility of antibacterial ability. As shown in Figure 5, the obvious absorption peaks at about 420nm wavelength appeared in curves on the treated cotton fabrics, which is consistent with the absorption peak of the silver nanoparticle solution [7]. The above results showed that the Ag NPs could be treated onto the surface of the cotton fabrics.

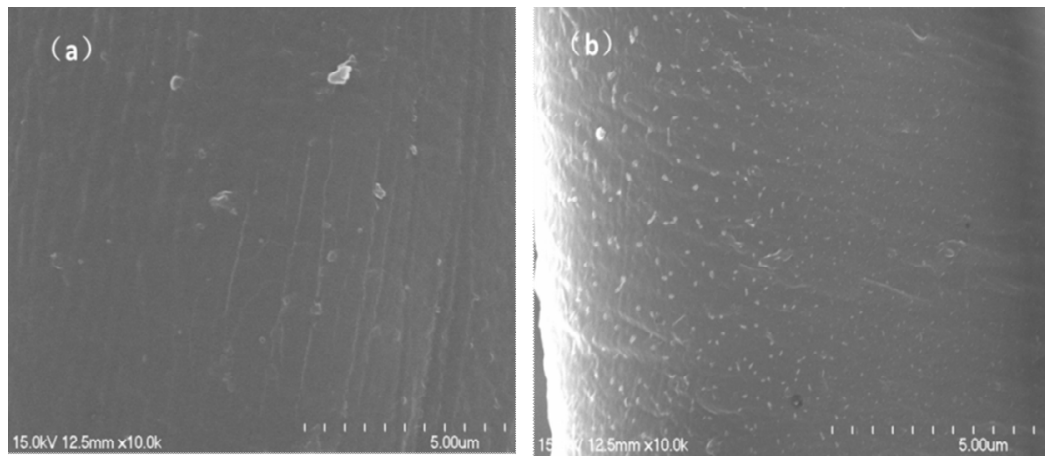

Figure 4. The SEM images of the surface of cotton fabrics:(a) original cotton fabric (b) nanosilver treated cotton fabric.

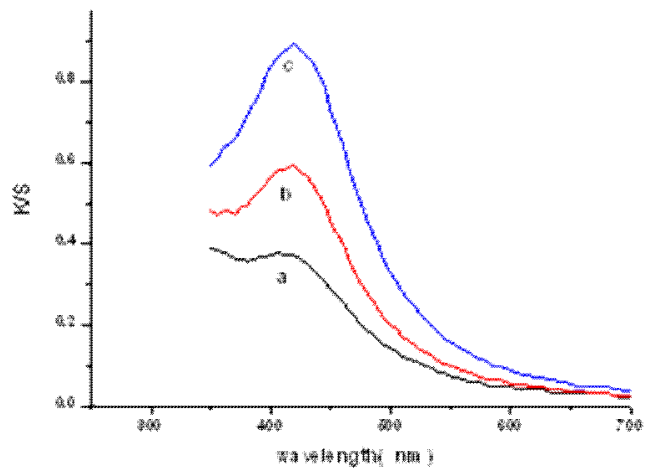

Figure 5. K/S spectrum of Ag NPs treated cotton fabrics, $\left[\mathrm{AgNO}_{3}\right]=0.017 \mathrm{~g} / \mathrm{l}$ (a) , $0.085 \mathrm{~g} / \mathrm{l}$ (b) , $0.17 \mathrm{~g} / \mathrm{l}$ (c), $\left[\mathrm{RSD}-\mathrm{NH}_{2}\right]=2 \mathrm{~g} / \mathrm{l}$.

\section{Antibacterial activity of the Ag NPs Treated Cotton fabrics}

The WI, silver content and the antibacterial rate against S. aureus and E.coli of the cotton fabric treated by Ag NPs were shown in Table 1. The samples( $a, b$ and c) on the Table 1 is that the cotton fabrics were treated by using $2 \mathrm{~g} / 1 \mathrm{RSD}-\mathrm{NH}_{2}$ solution, respectively, mixed with $0.017 \mathrm{~g} / 1,0.085 \mathrm{~g} / \mathrm{l}$, $0.17 \mathrm{~g} / 1 \mathrm{AgNO}_{3}$ solution. As a reference, the whiteness of the original cotton fabric is 89.10 . The finished cotton fabrics have excellent antibacterial rates against S.aureus and E. coli, which are more than $99 \%$. When the silver content of cotton fabrics increased from 114.65 to $156.79 \mathrm{mg} / \mathrm{kg}$, the antibacterial rate had no obvious change, but the WI changed a little. Therefore, the concentration of the solution was $0.017 \mathrm{~g} / \mathrm{l}$, the silver nanoparticle-treated cotton fabrics can showed 
an excellent antibacterial property and satisfied whiteness.

Table 1 The WI,silver content, and antibacterial rate of nanosilver-treated cotton fabrics

\begin{tabular}{ccccccc}
\hline \multirow{2}{*}{ Samples } & Silver content & WI & \multicolumn{4}{c}{ Antibacterial activities } \\
\cline { 4 - 6 } & $(\mathrm{mg} / \mathrm{kg}$ fabric $)$ & & \multicolumn{2}{c}{ Surviving cells(CFU/ml $)$} & \multicolumn{2}{c}{ Reduction(\%) } \\
\cline { 4 - 6 } & & & S.aureus & E.coli & S.aureus & E.coli \\
\hline untreated & - & 89.10 & $3.64 \times 10^{6}$ & $1.20 \times 10^{6}$ & - & - \\
a & 114.65 & 82.17 & $4.56 \times 10^{3}$ & $1.32 \times 10^{3}$ & 99.87 & 99.89 \\
b & 138.82 & 78.61 & $1.13 \times 10^{3}$ & $9.60 \times 10^{2}$ & 99.97 & 99.92 \\
c & 156.79 & 74.94 & $2.21 \times 10^{3}$ & $1.23 \times 10^{2}$ & 99.93 & 99.99 \\
\hline
\end{tabular}

The antibacterial activity of the Ag NPs treated Cotton fabrics after repeated washings

As one of the most important factors to consider for the antimicrobial finishing of cotton fabrics is its launderings durability. The cotton fabrics treated by the mixed solution with the $0.017 \mathrm{~g} / 1$ $\mathrm{AgNO}_{3}$ and $2 \mathrm{~g} / \mathrm{l} \mathrm{RSD}-\mathrm{NH}_{2}$, which were laundered 5 times, 10 times, 20 times, and the results were given in Table 2. With the washing times increased, the silver content slightly decreased from 114.65 to $98.89 \mathrm{mg} / \mathrm{kg}$, while the corresponding whiteness increased from 82.17 to 86.56 . It was surprising that the antibacterial rate was still more than $98.98 \%$ for S. aureus and $99.02 \%$ for E. coli after 20 washings. The excellent laundering durability of the silver nanoparticle-treated cotton fabrics may be caused by the following reasons. On one hand, some amino and imino groups of RSD-NH $\mathrm{N}_{2}$ form a silver ammonia complex with Ag NPs, which easily penetrate into the amorphous zone of cotton fabrics. On the other hand, the van der Waals force between molecules, as well as the hydrogen bond, will enhance the bonding between silver particles and cotton fabrics.

Table 2 The WI,silver content, and antibacterial rate of nanosilver-treated cotton fabrics after repeated washings

\begin{tabular}{cccccccc}
\hline \multirow{2}{*}{ Samples } & $\begin{array}{c}\text { Laundering } \\
\text { cycles }\end{array}$ & $\begin{array}{c}\text { Silver content } \\
(\mathrm{mg} / \mathrm{kg} \text { fabric })\end{array}$ & & WI & \multicolumn{4}{c}{ Antibacterial activities } \\
\cline { 5 - 7 } & & & & Surviving cells $(\mathrm{CFU} / \mathrm{ml})$ & \multicolumn{2}{c}{ Reduction(\%) } \\
\cline { 5 - 7 } & & - & 89.10 & $3.64 \times 10^{6}$ & $1.20 \times 10^{6}$ & - & - \\
untreated & - & 114.65 & 82.17 & $4.56 \times 10^{3}$ & $1.32 \times 10^{3}$ & 99.87 & 99.89 \\
Silver-trea & - & 105.39 & 82.88 & $3.71 \times 10^{4}$ & $1.21 \times 10^{4}$ & 98.98 & 98.99 \\
ted fabrics & 5 & 102.89 & 83.43 & $1.86 \times 10^{4}$ & $8.88 \times 10^{2}$ & 99.49 & 99.26 \\
& 10 & 98.89 & 86.56 & $3.71 \times 10^{4}$ & $1.18 \times 10^{4}$ & 98.98 & 99.02 \\
\hline
\end{tabular}

\section{Ultraviolet Resistance of Ag NPs Treated Cotton fabrics}

The UPF and transmittance of UV radiation were measured to investigate the ultraviolet resistance of the Ag NPs treated cotton fabric. Table 3 showed the ultraviolet resistance of the cotton fabric before and after nano-silver colloidal particles treatment and the samples (a, b and c) on the Table 3 is the same to the Table 1. The UPF of the untreated cotton fabric is only 1.7, which showed a bad ultraviolet resistance. After treated by nanosilver colloidal particles, the UPF of the treated cotton fabric increased from 1.7 to 14.9. As the concentration of $\mathrm{AgNO}_{3}$, the UPF of treated fabrics changed from 14.9 to 22.7.The result showed that the ultraviolet resistance of nano-silver treated cotton fabric improved and was affected by the concentration of $\mathrm{AgNO}_{3}$. 
Table 3 The ultraviolet resistrance of nanosilver-treated cotton fabrics

\begin{tabular}{cccc}
\hline samples & $\mathrm{T}_{\mathrm{UVA}}(\%)$ & $\mathrm{T}_{\mathrm{UVB}}(\%)$ & $\mathrm{UPF}$ \\
\hline untreated & 42.98 & 52.75 & 1.7 \\
$\mathrm{a}$ & 10.03 & 4.1 & 14.9 \\
$\mathrm{~b}$ & 10.69 & 2.74 & 18.6 \\
$\mathrm{c}$ & 11.93 & 1.73 & 22.7 \\
\hline
\end{tabular}

\section{Conclusion}

In summary, the Ag NPs showed a spherical structure with diameter of around $10 \mathrm{~nm}$, its absorption peak is about $420 \mathrm{~nm}$ and affected by the concentration of nano-silver solution. When it used to modify the cotton fabrics, the Ag NPs distributed uniformly on the surface, and the treated fabrics have an obvious absorption peak around 420nm and excellent antibacterial rates against S.aureus and E. coli, which are more than 99\%. When the lower concentration of the $\mathrm{AgNO}_{3}$ colloidal solution was $0.017 \mathrm{~g} / \mathrm{l}$, the antimicrobial ability of cotton fabrics showed an excellent antibacterial property and satisfied whiteness. After washed 20 times, the ratio of antibacterial activity is still more than $98.98 \%$ for S.aureus and $99.02 \%$ for E. coli. Upon increasing launderings from 5 to 20, antimicrobial activities of Ag NPs treated cotton fabrics change a little, and the corresponding whiteness increased from 82.17 to 86.56.In addition, the ultraviolet resistance of nano-silver treated cotton fabric improved and was affected by the concentration of $\mathrm{AgNO}_{3}$, the value of UPF changed from 1.7 to 22.7 .

\section{Acknowledgements}

This research was funded by Jiangsu Overseas Research \& Training Program for University Prominent Young \& Middle-aged Teachers and Presidents in 2016, Technical guidance project of China textile industry federation (2014044), Top-notch Academic Programs Project of Jiangsu Higher Education Institutions ( PPZY2015C254).

\section{References}

[1] H.J. Lee, S. H. Jeong: submitted to Textile Research Journal(2005)

[2] W.K. Sona, J.H. Youk, W.H. Park: submitted to Carbohydrate Polymers(2006)

[3] N. Sapiam, C.Homklinchan, R Larpudomlert: submitted to Journal of Applied Sciences (2010)

[4] S. Shen, S. Ye, X. song, M. Li, Y. Fang: submitted to Journal of Transaction of the Chinese Society of Agricultural Engineering (2012)

[5] D.S. Zhang, L. Chen, C.F.Zang,Y.Y.Chen,H.Lin: submitted to Carbohydrate Polymers (2013)

[6] G.Y. Zhang, Y. Liu, X.L. Gao, Y.Y. Chen: submitted to Nanoscale Research Letters(2014)

[7] F. Zhang, X. Wu, Y. Y. Chen,H.Lin : submitted to Fiber and Polymers(2009) 